\title{
Effects of parasitic castration on growth, reproduction and population dynamics of the marine snail Cerithidea californica
}

\author{
Kevin D. Lafferty \\ Department of Biological Sciences, University of California, Santa Barbara, California 93106, USA
}

\begin{abstract}
I investigated the prediction that parasitic castrators can reduce host population density. A survey of the salt marsh snail Cerithidea californica suggested a negative association between snail density and the prevalence of larval trematodes which castrate parasitized snails. Field experiments were conducted to determine the mechanisms by which larval trematodes might affect snail populations. Manipulations of snail density and trematode prevalence indicated that larval trematodes reduced the reproductive output of the snail population and caused differential mortality of parasitized hosts. Furthermore, an effect of competition between parasitized and unparasitized snails was detected by comparing snail growth rates. As expected, this was deemed to be a simple density effect and was not due to any special qualities of the parasitized snails. Analysis of chlorophyll a levels in the sediment suggested that competition may have occurred due to limited amounts of food. These results suggest that larval trematodes can reduce snail population densities by reducing snail reproduction, competing with parasitized snails for food and increasing the mortality rates of parasitized snails.
\end{abstract}

\section{INTRODUCTION}

Parasitic castrators have been suggested as regulators of host populations because, like predators or parasitoids, they directly reduce the reproductive output of the host population (Kuris 1973, 1974). Although the effects of parasitic castration have been largely overlooked, parasites commonly castrate a large number of crustacean, mollusk and echinoderm hosts. There is some previous evidence that parasitic castrators may affect host population density. For example, the addition of trematode eggs to ponds results in a decrease, or even local extinction of host snail populations (Lie 1973. Combes 1982). Furthermore, life table data indicate that the prevalence of trematodes is associated with reduced snail replacement rates (Brown et al. 1988). In addition, it has been suggested that increases in the prevalence of parasitic castrating barnacles are associated with declines in the yields of crustacean fisheries (Lester 1978). In this study, I attempted to determine if and how parasitic castration reduces the population density of the salt marsh snail Cerithidea californica.
A theoretical treatment of the effects of parasitic castration on host populations is provided in a model by Blower \& Roughgarden (1987) of an isopod that castrates its barnacle host. This model indicates that parasitic castration can regulate the barnacle population under certain conditions. Experimental manipulations in this system showed that the per-capita risk of castration is greater in high density or aggregated barnacle populations, presumably because settling male parasites are attracted to pheromones emitted by adult female parasites (Blower \& Roughgarden 1989). This may cause a regulating effect on barnacle populations since the isopod would tend to reduce the per-capita reproductive output of barnacles during conditions when barnacle populations were high. However, because this density-dependent effect relies on the protandrous mating system of the isopod parasite, it is not clear whether general predictions about parasitic castration can be made from these results.

By what means might parasitic castrators affect host population density? Castration of male and female hosts implies that the reproductive output of a population should be reduced. Furthermore, pathology asso- 
ciated with castration could lead to increased host mortality. However, the effects of parasitic castration are not necessarily entirely direct. When predators or parasitoids remove an individual from a prey population, resources are freed for the remaining prey or host individuals. In contrast, in the case of parasitic castration, castrated hosts remain alive and use the same resources as unparasitized hosts. For this reason, in addition to directly castrating their hosts, parasitic castrators may indirectly affect unparasitized hosts by competing with them for resources (Hughes 1986). Indeed, because the future reproductive value of a castrated host is eliminated, the parasitically castrated host may be conceived as a parasite genome that expresses a host phenotype (O'Brien \& Van Wyk 1985). Because host and parasite share the same phenotype. intraspecific competition between unparasitized hosts will be accompanied by 'interspecific' competition between unparasitized hosts and parasitic castrators. If parasite recruitment is closed, competition between parasitized and unparasitized hosts will lead to a decline in the parasite population; otherwise, this competition will result in a decrease in the density of unparasitized hosts (Lafferty 1991).

To test the prediction of a negative correlation between parasitic castrator prevalence and host density, and to determine the relative importance of direct (castration) and indirect (competition) effects of parasitic castration, I studied the marine snail Cerithidea californica, which is the first intermediate host for the larvae of several trematode species (Martin 1955, 1972). C. californica is a dioecious, marine, prosobranch snail that commonly occurs in salt marshes and on tidal mud flats from Tomales Bay in northern California, USA, to Laguna San Ignacio on the outer coast of Baja California, Mexico (MacDonald 1969). It feeds on epibenthic microalgae (mostly diatoms) at high tide, and net movement is rarely more than $3 \mathrm{~m} \mathrm{mo}^{-1}$ (Whitlatch \& Obrebski 1980). Intraspecific competition may be a factor regulating $C$. californica populations as snails are regularly dispersed and have higher mortality at artificially high densities (McCloy 1979). Snails apparently live for many years and reproduction and growth are seasonal. Egg strings containing approximately 1300 eggs are most common between June and August (Race 1981) and hatch 4 to 6 wk after being laid (McCloy 1979). Development is direct such that snails hatch into crawl-away larvae (Race 1981).

In Cerithidea californica, the site of asexual larval trematode development is often the gonad: snails of both sexes (Lafferty 1993) are nearly always permanently castrated by a single parasite species (Yoshino 1975, Sousa 1983, Kuris 1990). Castrated snails do not show copulatory behavior (Sousa 1983) but could not otherwise be distinguished in behavior, morphology or distribution, from unparasitized snails. Trematode prevalence (the proportion of hosts that are parasitized; Margolis et al. 1982) can be as high as $95 \%$ (Lafferty 1993) and is probably a function of host age as is evidenced by a strong positive relationship between snail size class and trematode prevalence (Sousa 1983, Kuris 1990). Because trematodes have indirect (multiple host) life cycles, parasites cannot pass directly from snail to snail. Instead, most trematodes pass through a second intermediate host on their way to vertebrate definitive hosts which are generally migratory shore birds. Since these birds disperse over a geographic scale that is larger than the snail population, there may be considerable immigration to the parasite population (Kuris 1990, Sousa 1990, Kuris \& Lafferty 1992). The open recruitment of these trematodes makes it more likely that snail density will be reduced by interspecific competition with trematodes (Lafferty 1991).

I surveyed natural snail populations and found a negative correlation between snail density and prevalence of trematodes. A manipulation of snail density and larval trematode prevalence indicated that larval trematodes reduced the reproductive output of their host snail population. In addition, the presence of parasitized snails reduced the growth rate of unparasitized snails and parasitized snails suffered differentially high mortality.

\section{MATERIALS AND METHODS}

This study was conducted at the 120 acre ( $48.5 \mathrm{ha}$ ) Carpinteria Salt Marsh Reserve, a unit of the University of California's Natural Reserve System. Carpinteria Salt Marsh is a well preserved system of tidal channels that wind through beds of pickleweed Salicornia spp. Cerithidea californica occur in a band along the channel banks (Page \& Lafferty 1993). A map of the marsh was used to find all channels that were within $100 \mathrm{~m}$ access from Apple Road. Channel sites were marked on the map at roughly $50 \mathrm{~m}$ intervals. Each site was investigated to determine if snails were present and whether the mud was stable enough for me to walk through. A random number generator was then used to choose 8 of those sites deemed suitable for sampling and manipulation.

Population survey. The snail population was surveyed in an attempt to test the predicted negative correlation between snail density and parasite prevalence. Within a site, however, prevalence increases with snail size, while among sites, snail density decreases with snail size. Therefore, one would expect to find a negative association between density and prevalence because of the variation in snail size among 
sites. My goal was to investigate the prediction independent of variation in size among sites. Sampling for snail density and prevalence was conducted as follows

A transect line was placed across each tidal channel from the upper vegetated margin of one bank to the center of the channel (or to the lower limit of the distribution of snails). Adjoining $700 \mathrm{~cm}^{2}$ circular 'quadrats' were placed along the transect, and the number and size of the snails in each quadrat were recorded. Two extra quadrats, one on each side of the quadrat with the highest density, were placed at a distance of $1 \mathrm{~m}$ from, and perpendicular to, the transect line. Snails from these additional quadrats, as well as from the quadrat with the highest density, were collected. These 3 quadrats were used to characterize snail population density and size distribution. The other quadrats were not included in the density estimate because the snails showed vertical zonation. Since salt marsh channels vary in their widths and bank slopes, sampling from the vertical zone with the highest density allowed a standardized comparison of snail density among sites.

Because older, and hence larger, snails have had a longer opportunity to become parasitized, the prevalence at a site may be a function of the risk of castration and the age or size distribution of the host population (Sousa 1983). To reduce the effect of the size structure of the host population on my estimate of trematode prevalence, I sampled 100 snails of the same size (20 to $25 \mathrm{~mm}$ ) at the same time as the survey from the dense zone surrounding the transect at each site. Sampling was consistent among sites. All collected snails were measured, dissected and assayed for the presence of larval trematodes, which were identified to species, and parasitic castration. The rediae or sporocysts of all but one of these species of trematodes displaced the gonad and digestive gland of the snail in patent infections. The non-castrating species was rare, and I omitted it from my estimate of prevalence.

Two other potential sources of variation in snail density are snail size and habitat quality. Since a larger snail probably consumes more resources than a small one, the number of snails that are able to occupy an area may decline with mean snail size. The resources available at a site may also limit the upper density of snails. The habitat quality of a site was estimated experimentally as the mean growth rate of caged snails of standardized sizes and densities (the methodology for this procedure is described below). A multiple regression of density as the dependent variable with prevalence (20 to $25 \mathrm{~mm}$ snails), mean size and 'habitat quality' (growth rate of caged snails) as independent variables was used to investigate the influence of parasite prevalence on host density while holding the effects of snail size and habitat quality constant.
Effects of larval trematodes on unparasitized snails. I investigated the prediction that a removal of parasitized snails would increase the fitness of the remaining unparasitized snails. To separate the effects of density and prevalence, I manipulated the two independently in a field experiment with 2 snail density levels and 2 prevalence levels as treatments. Snail growth, mortality and egg production were used as dependent variables to assess treatment effects. The survey data from the high density zone ( 3 quadrats per site by 8 sites) were pooled to determine the density ( 25 snails per quadrat, standard deviation $=14$ ), prevalence $(52 \%$, standard deviation $=24 \%$ ), and size distribution of the snail population. The relative frequencies of snails in each size class were multiplied by the mean snail density to produce a representative sizefrequency histogram. This histogram consisted of 13 parasitized snails and 12 unparasitized snails per quadrat.

The representative size frequency histogram was used as a template for the $2 \times 2$ factorial design shown in Fig. 1. Four treatments were composed of the following types of snails: (A) 12 unparasitized and 13 parasitized snails, (B) 25 unparasitized snails, (C) 6 unparasitized snails and 7 parasitized snails, and (D) 12 unparasitized snails. Treatment (A) served as a control for mean density and prevalence, while Treatment (D) served as an

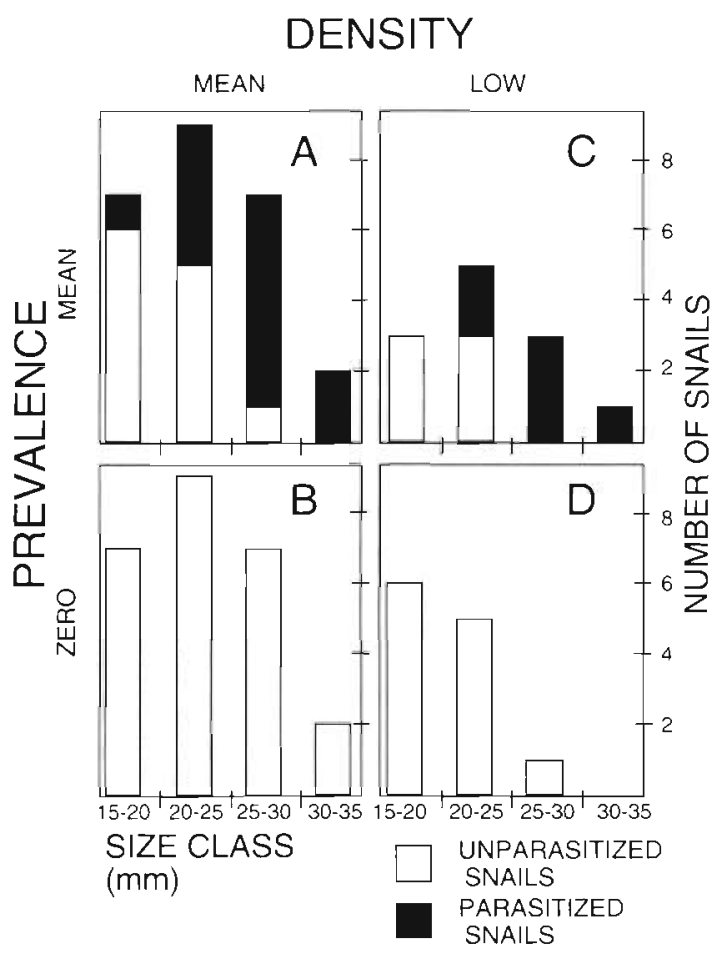

Fig. 1 Diagrammatic representation of one block of a $2 \times 2$ matrix of density and prevalence. Each treatment was enclosed in a cage and each block was replicated 8 times 
experimental removal of the parasitic castrator. Treatments (B) and (C) allowed the independent assessment of the effects of prevalence and density respectively.

To obtain snails for 8 replicates of the 4 treatments, additional snails were collected in the same fashion at the same 8 sites, mixed, rinsed, measured, and placed in individual plastic compartments (parts boxes) filled with filtered sea water. The compartmentalized snails were then held at room temperature under incandescent light for 12 to $24 \mathrm{~h}$. Under these conditions, parasitized snails release (shed) cercarial stages into the water (Sousa 1983). The compartment of each snail was checked for cercarial stages over the following $2 \mathrm{~d}$. Unparasitized snails, and snails parasitized with the most prevalent trematode species, Euhaplorchis californiensis ( $75 \%$ of all infections), were then assigned randomly, by size, to one of the replicated treatments.

After being divided into experimental populations in late June 1990, snails were measured again and individually labeled with numbered plastic tags (electronic wire markers) attached to the shell with 'Krazy glue' Each experimental unit was caged in a $700 \mathrm{~cm}^{2} \mathrm{cir}$ cular enclosure of fine mesh vexar screen which extended $25 \mathrm{~cm}$ above and $11 \mathrm{~cm}$ below the mud surface and which was anchored with four $30 \mathrm{~cm}$ PVC pipes, after Race (1982). To reduce shading effects, cages were not covered. This also permitted the entry and exit of an occasional Cerithidea californica or crabs (Pachygrapsus crassipes and Hemigrapsus oregonensis). Clams (Macoma nasuta, Tagelus californianus and Protothaca staminea) were also present within the enclosures. Treatment units were distributed according to a randomized complete block design. In addition to the 4 treatments, a cage control (cages with openings in the mesh walls) and an open control (an uncaged circular $700 \mathrm{~cm}^{2}$ area marked with PVC pipes) were included in each block. The blocks were placed in the dense zone at the 8 sites where the previously described survey was conducted

Data on size, abundance and eggs were collected at monthly intervals from July through October 1990. Monthly samples recovered a high percentage $(92 \%)$ of live, marked snails ( $n=1776$ recaptures). To estimate chlorophyli a levels (as mentioned below), 4 shallow sediment cores were taken from within each cage in July and August, using a modified $3 \mathrm{cc}$ syringe (after Page et al. 1992) These samples were then labeled and frozen. (analysis given below). After sediment cores were taken, newly laid egg strings, which were present July and August, and all snails (July through October) were removed from the cages and the surface of the sediment was smoothed by hand to equalize the disturbance between treatments. Egg strings and snails were brought to the laboratory at the end of each collecting period
In the laboratory, egg strings were measured (length in $\mathrm{mm}$ ). This provided an estimate of the total egg production of each caged snail population. Dividing this value by the number of uninfected snails in a treatment gave the per-capita egg production. Snails were checked twice for shedding cercariae and measured to determine growth. Previously 'unparasitized' snails that were observed to shed were dissected to confirm infection and replaced with non-shedding snails of the same size (see Lafferty 1991 for a discussion of false negative infections). Dead or missing individuals were counted and replaced. Occasionally, marked individuals that had not been detected in the previous census were recovered from the cages. These were assumed to have been present through the previous census periods. After all data were recorded, snails were returned to the cages within $48 \mathrm{~h}$

The total growth of unparasitized snails initially 15 to $20 \mathrm{~mm}$ and 20 to $25 \mathrm{~mm}$ in length were averaged separately for each site (these were the only 2 size classes of unparasitized snails represented in all treatments). These 2 growth rates were then averaged to provide a single value indicative of the growing conditions at a site (used in the multiple regression). The effects of density and prevalence on growth and egg production were investigated with model 1,2-way analysis of variance with site as a random block effect. From each cage, the average total growth of unparasitized snails initially 15 to $20 \mathrm{~mm}$ provided a single growth value for each cage in the analysis. Each block was considered a single replicate in the statistical analyses. Mortality was analyzed using Cochran's method (Everitt 1977), which allowed a comparison of mortality frequencies between parasitized and unparasitized snails independent of size class. Relative mortality rates of pooled treatments averaged by month were then estimated using a weighted least squares regression of mortality rate and initial size class. This value was taken from the midpoint of the regression where the error of the estimate is the smallest.

Resource limitation. I attempted to identify whether food resources were reduced at normal snail densities. To do this, I compared chlorophyll a levels on the mud surface following a manipulation of snail densities. This measure has been shown to be a good indicator of food resources for grazers in this environment (Page et al. 1992). Sixteen cages (as described previously) were placed in a line along a marsh channel at $1 \mathrm{~m}$ intervals. All snails were removed from half of the cages in an alternating fashion. This design maximized interspersion and is valid as long as the spacing interval of the treatments does not coincide with any periodically varying feature of the environment that strongly alters algal growth (Hurlbert 1984). Snails were not continually removed from these cages. After 1 mo (June 1991), 
one cage of each treatment was covered with drift kelp; therefore, these cages were excluded from the analysis. In the other cages, I found an average of 2.0 snails in the cages from which all the snails had been removed the previous month compared with an average density of 18.7 snails in the cages from which snails were not removed. I then took sediment samples from each cage as described previously. Levels of chlorophyll a were later determined from sediment samples using a spectrophotometer (Strickland \& Parsons 1968). I investigated associations between pigment concentration and snail density using correlation analysis, an unpaired $t$-test and, for the 4 treatment experiment, a model 1, 2-way repeated measures analysis of variance. All probability values mentioned are 2 -tailed unless otherwise noted

\section{RESULTS}

\section{Population survey}

As predicted, the multiple regression analysis indicated that after variation in snail size and habitat quality, measured as growth rate, were accounted for, there was a significant negative effect of prevalence on snail density $(t=-2.97, \mathrm{df}=4, \mathrm{p}=0.041)$. The mean snail size of a population was not correlated with the prevalence of castration of the 20 to $25 \mathrm{~mm}$ snails from that population ( $\mathrm{r}=0.280, \mathrm{df}=6, \mathrm{p}>0.05$ ). The latter indicated that my measure of prevalence was not affected by the size distribution of the population.

\section{Direct effects of larval trematodes on unparasitized snails}

Not surprisingly, there was a significant effect of prevalence on the egg production of the snail population combined over July and August (Table 1). For example, the total egg production of a caged population was 2.6 times higher when parasitized individuals were replaced by unparasitized individuals (Treatments A \& B). This demonstrated that larval trematodes directly reduced the reproductive output of the snail population.

Table 1. Cerithidea californica. ANOVA - total egg production

\begin{tabular}{|lrrrr|}
\hline Source & df & \multicolumn{1}{c}{ MS } & \multicolumn{1}{c|}{$F$} & \multicolumn{1}{c|}{$p$} \\
\hline Density & 1 & 44.469 & 1.3 & 0.270 \\
Prevalence & 1 & 342.246 & 10.1 & 0.006 \\
Site & 5 & 229.256 & 6.8 & 0.002 \\
D $\times$ P & 1 & 18.297 & 0.5 & 0.473 \\
Error & 15 & 33.827 & & \\
\hline
\end{tabular}

\section{DENSITY}

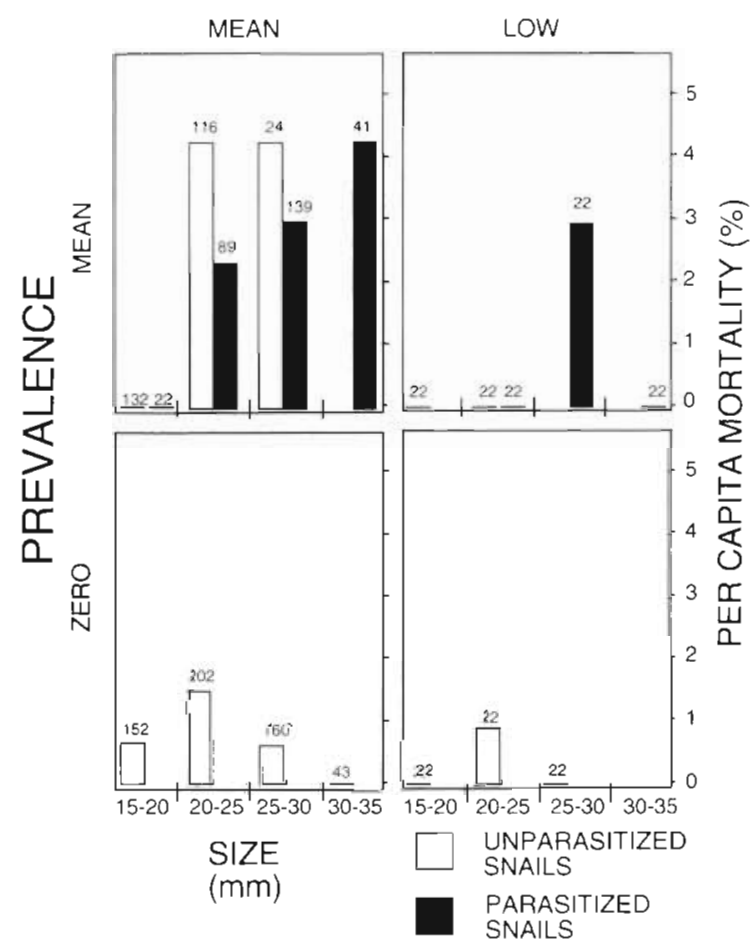

Fig. 2. Cerithidea californica. Per-capita mortality rates for each size class of snails over 3 mo. No significant differences in mortality existed among treatments. Mortality was higher for parasitized snails than for unparasitized snails. Numbers represent sample sizes

Parasitism also appeared to affect survivorship. The monthly mortality rate over the first 3 mo was estimated as $1.2 \%$ for unparasitized snails and $2.1 \%$ for parasitized snails (Fig. 2) (this difference was significant at the 1 -tailed level, Cochran's method, $Y=1.75$, $p=0.04)$. Unusually high mortality of an unknown cause in 2 October blocks was associated with a higher mortality for parasitized snails over unparasitized snails. From these 2 blocks, the monthly mortality rate was estimated as $29 \%$ for unparasitized snails and $49 \%$ for parasitized snails (Fig. 3). Although the mortality rate was high in these blocks, the degree of differential mortality was identical to that found during the rest of the experiment. For both the normal and high mortality cases, parasitized snails suffered 1.7 times higher mortality than unparasitized snails.

\section{Indirect effects of larval trematodes on unparasitized snails}

Evidence for the indirect effects of parasitic castration on unparasitized snails was found by comparing growth rates among the density treatments (Fig. 4). 


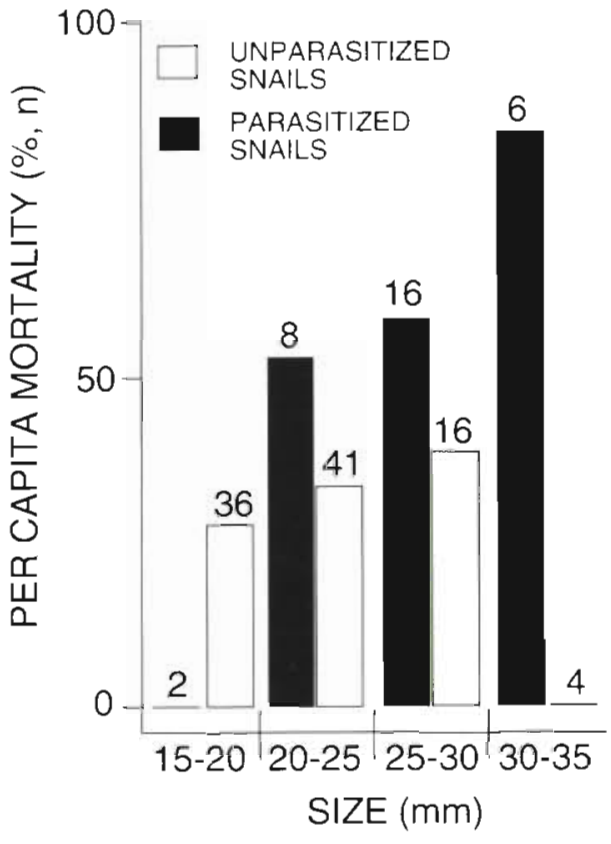

Fig. 3. Cerithidea californica. A comparison of per-capita mortality rates of unparasitized and parasitized snails from 2 blocks in October that suffered abnormally high mortality Numbers represent sample sizes

The analysis of variance indicated a significant effect of density on growth rates (Table 2). For example, over the 3 mo of the study, unparasitized snails that started in the 15 to $20 \mathrm{~mm}$ size class grew $4.8 \mathrm{~mm}$ in low density treatments (C \& D) and $3.6 \mathrm{~mm}$ in high density treatments $(A \& B)$. There was no evidence that the growth rate of unparasitized snails differed depending on whether they competed with parasitized snails or unparasitized snails. Unparasitized snails (15 to $20 \mathrm{~mm}$ ) grew $4.4 \mathrm{~mm}$ in low prevalence treatments (B \& D) and $4.0 \mathrm{~mm}$ in high prevalence treatments (A \& C); this difference was not statistically significant (Table 2). There was no significant effect of snail density on the growth of parasitized snails (Wilcoxon's signed rank test, $\mathrm{df}=7, \mathrm{p}>0.2$ ). The growth rate of parasitized snails, however, was very low (often zero) and was always less than the growth rate of unparasitized snails.

Other factors affected growth rates in the experiment. Sites varied in growing conditions as was evidenced by significant variation in the average growth rates of caged snails (Table 2). The average growth rates of caged snails over all treatments were used as estimates of habitat quality in the previous survey. As McCloy (1.979) found, there was a strong seasonal component to growth. Growth rates declined from July to September (Table 2). The growth data from October indicated that growth was lowest in this month but these data were not analyzed due to the unknown

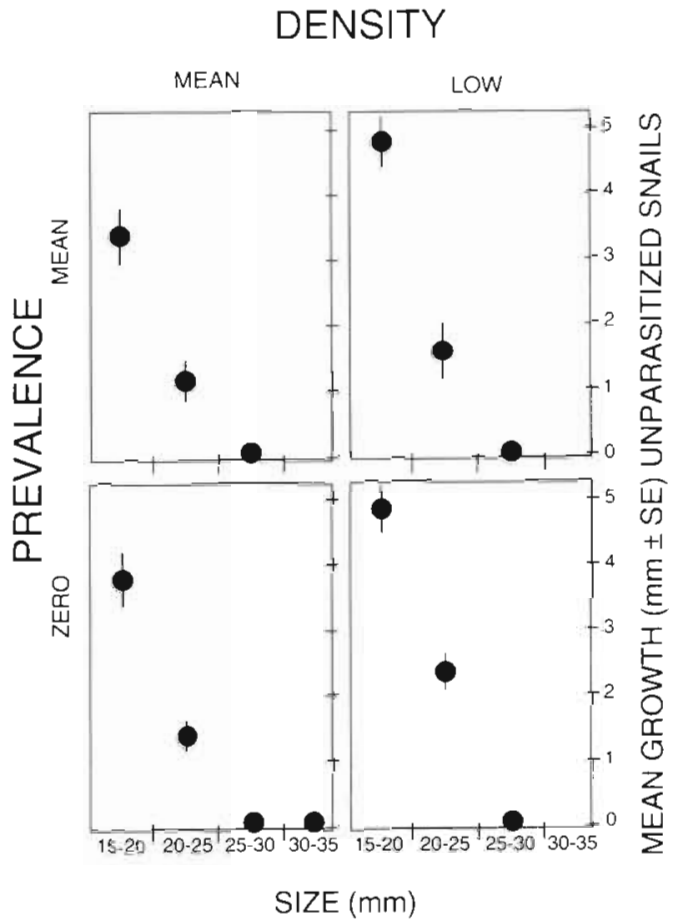

Fig. 4. Cerithidea californica. Three month growth rates (means and standard errors) of unparasitized snails (see Fig. 1). Low density treatments grew significantly faster than high density treatments

source of high mortality in two of the blocks. In addition, a cage effect existed to the extent that snail densities of sham cages were always lower than in open plots. For this reason, these growth rates were only used for comparative purposes and not used to develop snail growth curves.

There were no apparent treatment effects on the survivorship or per-capita egg production of unparasitized snails. High density treatments did not suffer a signifi-

Table 2. Cerithidea californica. ANOVA - growth of 15 to $20 \mathrm{~mm}$ uninfected snails

\begin{tabular}{|c|c|c|c|c|}
\hline Source & df & MS & $F$ & $p$ \\
\hline \multicolumn{5}{|c|}{ (A) Between months effects } \\
\hline Density & 1 & 3.58 & 14.0 & 0.001 \\
\hline Prevalence & 1 & 0.29 & 1.1 & 0.296 \\
\hline Site & 7 & 1.05 & 4.1 & 0.005 \\
\hline $\mathrm{D} \times \mathrm{P}$ & 1 & 0.03 & 0.1 & 0.728 \\
\hline Error & 21 & 0.26 & & \\
\hline \multicolumn{5}{|c|}{ (B) Within months effects } \\
\hline Month & 2 & 12.294 & 42.6 & 0.000 \\
\hline$M \times D$ & 2 & 0.422 & 1.5 & 0.243 \\
\hline $\mathrm{M} \times \mathrm{P}$ & 2 & 0.222 & 0.8 & 0.470 \\
\hline $\mathrm{M} \times \mathrm{S}$ & 14 & 0.501 & 1.7 & 0.084 \\
\hline $\mathrm{M} \times \mathrm{D} \times \mathrm{P}$ & 2 & 0.025 & 0.1 & 0.917 \\
\hline Error & 42 & 0.289 & & \\
\hline
\end{tabular}


Table 3. Cerithidea californica. ANOVA - per capita egg production

\begin{tabular}{|lrrrr|}
\hline Source & df & MS & $F$ & p \\
\hline Density & 1 & 3.754 & 1.0 & 0.338 \\
Prevalence & 1 & 2.184 & 0.6 & 0.462 \\
Site & 5 & 20.406 & 5.3 & 0.005 \\
D $\times$ P & 1 & 0.277 & 0.1 & 0.792 \\
Error & 15 & 3.834 & & \\
\hline
\end{tabular}

cantly higher mean per-capita mortality (Cochran's method, $Y=1.64, p>0.5)$. This was surprising considering that McCloy (1979) found significantly increased mortality in artificially high densities. Mean per-capita egg production of unparasitized snails, measured as the length of egg strings, was not significantly different between low density (19.2 mm) and high density (11.5 mm) treatments (Table 3). There was also no significant effect of prevalence on per-capita (unparasitized) egg production (Table 3 ). In addition, a significant correlation was not detected among sites between egg production and growth rates $(\mathrm{r}=-0.217$, $\mathrm{df}=4$, $p>0.05)$. Therefore, although parasitic castration had a large impact on the egg production of the experimental populations, it was not evident that competition from parasitized snails also indirectly affected the egg production of unparasitized individuals.

\section{Resource limitation}

The snail resource limitation experiment suggested that resources were reduced at the mean snail densities in Carpinteria Salt Marsh. Chlorophyll a (live plant material) levels were negatively correlated with snail density $(r=-0.704, p<0.01, d f=12)$ and were 1.9 times higher in cages where snails had been removed (2.6 $\mathrm{mg} \mathrm{g}^{-1}$ sediment) than cages where snails had not been removed $\left(1.4 \mathrm{mg} \mathrm{g}^{-1}\right.$ sediment) $(t=2.9, \mathrm{df}=6, \mathrm{p}=$ $0.03)$. Inspection of the residuals from the correlation indicated no spatial autocorrelation between treatment and chlorophyll $a(t=-0.14, \mathrm{df}=6, \mathrm{p}=0.893)$.

An analysis of variance of the $2 \times 2$ factorial experiment indicated that there were no significant differences in pigments due to density or prevalence (Table 4) when July and August chlorophyll a were analyzed as repeated measures. Treatment cages did not differ from open plots ( $t=-1.13, \mathrm{df}=7, \mathrm{p}=0.294$ ) or sham cages $(t=0.721$, df $=7, p=0.494)$. However, chlorophyll a levels were higher in August than in July (Table 4) when low density plots had $1.02 \mathrm{mg} \mathrm{g}^{-1}$ chlorophyll $a$ and high density plots had $0.78 \mathrm{mg} \mathrm{g}^{-1}$ chlorophyll $a$. The level of chlorophyll a (pooled for all treatments, averaged over July and August) varied sig-
Table 4. Cerithidea californica. ANOVA - chlorophyll a concentrations

\begin{tabular}{|c|c|c|c|c|}
\hline Source & df & MS & $F$ & $\mathrm{p}$ \\
\hline \multicolumn{5}{|c|}{ (A) Between months effects } \\
\hline Density & 1 & 0.003 & 2.0 & 0.176 \\
\hline Prevalence & 1 & 0.001 & 0.5 & 0.469 \\
\hline Site & 7 & 0.012 & 7.1 & 0.000 \\
\hline $\mathrm{D} \times \mathrm{P}$ & 1 & 0.000 & 0.1 & 0.724 \\
\hline Error & 20 & 0.002 & & \\
\hline \multicolumn{5}{|c|}{ (B) Within months effects } \\
\hline Month & 1 & 0.019 & 12.3 & 0.002 \\
\hline$M \times D$ & 1 & 0.002 & 1.2 & 0.293 \\
\hline$M \times P$ & 1 & 0.000 & 0.0 & 0.886 \\
\hline$M \times S$ & 7 & 0.002 & 1.5 & 0.220 \\
\hline$M \times D \times P$ & 2 & 0.000 & 0.0 & 0.994 \\
\hline Error & 20 & 0.002 & & \\
\hline
\end{tabular}

nificantly among sites (Table 4) and was positively correlated with the mean snail growth rate (as described above) at that site $(r=0.690, p=0.058$, df $=6)$. This association is only significant for the 1 -tailed prediction that chlorophyll a levels adequately represent food resources and increased growth rates (and is subject to problems of pooling treatments).

\section{DISCUSSION}

The negative association between density and prevalence supports the hypothesis that parasitic castration can reduce host population density. An untested alternative explanation for the negative correlation between density and prevalence is that the prevalence of parasitism and predation are positively correlated. This might occur if birds, the definitive hosts of trematodes, simultaneously reduce snail density via predation and increase prevalence by passing trematode eggs. Although some birds are known to prey on small Cerithidea californica, there is no indication that bird predation is an important factor regulating C. Californica populations (McCloy 1979, Race 1982, Sousa 1993). Even if snail population densities in Carpinteria Salt Marsh are reduced by parasitic castration, parasites are not necessarily regulating the snail population. Because trematodes have complex lifecycles and their definitive hosts are mobile, strong feedback between increased host density and infection rates is unlikely and I would not expect higher rates of castration in cases where the snail population is extremely high. Clearly, the primary productivity at a site and intraspecific competition for resources are more likely to be important regulating factors in this sense. Also, the shore crab Pachygrapsus crassipes may negatively affect snail population densities in a 
non-density-dependent fashion where crab densities are high (McCloy 1979, Sousa 1993).

Trematodes might directly affect the snail population by reducing the egg production of the snail population and by increasing snail mortality rates. The reduction in egg production observed in this system is consistent with the most basic predictions that one could make for the effect of parasitic castration on host populations. However, for a reduction in egg production to have a negative effect on local population density, there must be a reduction in the recruitment of juveniles back into their local parent population. As previously mentioned, the recruitment dynamics of this species suggest that this assumption is reasonable. Because parasitized snails have higher death rates, the parasite can further depress the host population in a manner that is somewhat analogous to a predator. An important difference, however, is that the death of a parasitized host also results in the death of a larval trematode. Differential mortality of parasitized Cerithidea californica has been found to occur when snails are parasitized with certain trematode species in the laboratory under conditions of low dissolved oxygen but not during normal conditions or other environmental stresses (Sousa \& Gleason 1989). Overall, I found that mortality was 1.7 times higher for parasitized snails than unparasitized snails.

Competition between parasitized snails and unparasitized snails reduced the growth rates of unparasitized snails. This was apparently a simple density effect; it did not appear that the infection status of a snail influenced how that snail affected unparasitized snails. There is no evidence that parasitized snails compete with unparasitized snails for mates; parasitized snails do not display mating behavior (Sousa 1983), nor do parasitized females store sperm (Lafferty 1991). However, parasitized snails are generally larger (older) than unparasitized snails and therefore might consume more resources. Alternatively, unparasitized snails might indirectly benefit from the parasitism of their neighbors because the latter produce no offspring which would compete with their offspring.

The increase in chlorophyll a levels in areas where snails were excluded suggests that epibenthic diatoms may be a potentially limiting food resource for which snails compete exploitatively. For this density effect on snail growth to impact the snail population, it would be necessary for it to result in decreased fitness of unparasitized snails. I did not search for a size-fecundity relationship because it was difficult to identify which snails laid which eggs. Also, despite the fact that snails in. low density treatments produced an average of $50 \%$ more eggs than snails in high density treatments, this large difference was not statistically significant. The wide variation in egg production and the small number of replicates used in this study may have prevented the detection of a biologically significant effect.

In conclusion, it appears that larval trematodes can potentially reduce Cerithidea californica populations because egg production is decreased by parasitic castration. In addition, castrated snails remain alive and feed on the same limited supply of epibenthic microalgae as unparasitized snails. Therefore, larval trematodes do not increase the fitness of the remaining unparasitized individuals as a predator might. Instead, they change the form of competition from intraspecific to interspecific due to the simple reason that parasitized snails behave and function as unparasitized snails. Snails should evolve defense strategies against trematodes, and there is evidence that populations of C. californica under high risk of parasitism by trematodes have evolved earlier maturation to increase their chances of reproduction (Lafferty 1993).

Parasitic castrators may have some general and applied importance. If parasitic castrators are able to reduce host densities, they might be useful as specific biological control agents (Kuris 1973). Crustaceans serve as definitive hosts for a wide range of parasitic castrators such as rhizocephalan barnacles and entoniscid isopods and for symbiotic nemertean egg predators, which at high intensities may kill all the eggs in the host clutch. These parasites might be used to control alien crab species such as the European shore crab Carcinus maenas. Alternatively, these parasites may have a negative economic impact if they reduce the population density or stability of commercially fished hosts (Wickham 1980, Sloan 1984, Kuris et al. 1991, Kuris 1992, Kuris \& Lafferty 1992). Because nemerteans are most commonly found on female crabs and rhizocephalans feminize their hosts, traditional efforts to manage a fishery (i.e. protection of females) may promote an increase in the prevalence of these parasites (Kuris \& Lafferty 1992). In general, because parasitic castrators are relatively common among marine invertebrate hosts, they may play a more important role in determining the abundance of these populations than previously thought.

Acknowledgements. This work was aided by funds from the NOAA National Sea Grant College Program, U.S. Dept of Commerce, under grant \# NA89AA-D-SG138, project \# E/G108 through the California Sea Grant College, and in part by the California State Resources Agency, a UCSB General Affiljates Scholarship and the E. S. Burley Graduate Scholarship for Outstanding Research Achievement. C. Levick and D. Sammond assisted with field and lab work. D. Canestro, I. Davila, E. Diaz de León, T Huspeni, A. Kuris, C. Sandoval, T Stevens, and $T$ Vincent assisted with field work. H. Page and C. Soiseth helped with the chlorophyll analysis. T Huspeni, A. Kuris, S. Rothstein, C. Sandoval, R. Warner and anonymous reviewers provided valıable comments on the manuscript. 


\section{LITERATURE CITED}

Blower, S., Roughgarden, J. (1987). Population dynamics and parasitic castration: a mathematical model. A.m. Nat. 129 $730-753$

Blower, S., Roughgarden, J. (1989). Parasites detect host spatial pattern and density: a field experiment analysis Oecologia 78: 138-141

Brown, K. M., Leathers, B. K., Minchella, D. J. (1988). Trematode prevalence and the population dynamics of freshwater pond snails. Am. Midl. Nat. 120:289-301

Combes, C. 1982). Trematodes: antagonsm between species and sterilizing effects on snails in biological control Parasitology 84: 151-175

Everitt, B. S. (1977). The analysis of contingency tables. Chapman and Hall, London

Hughes, R. N. (1986) A functional biology of marine gastropods. The John Hopkins University Press, Baltimore, MD

Hurlbert, S. H. (1984). Pseudoreplication and the design of ecological field experiments. Ecol. Monogr. 54: 187-211

Kuris, A. M. (1973). Biological control: implications of the analogy between the trophic interactions of insect pestparasitoid and snail-trematode systems. Exp. Parasitol. 33 $365-379$

Kuris, A. M. (1974). Trophic interactions: similarity of parasitic castrators to parasitoids. Q. Rev. Biol. 49: 129-148

Kuris, A. M. (1990). Guild structure of larval trematodes in molluscan hosts: prevalence, dominance and significance in competition. In: Esch, G., Bush, A., Aho, J. (eds.) Parasite communities: patterns and processes. Chapman and Hall, New York, p. 69-100

Kuris, A. M. (1992). A review of patterns and causes of crustacean brood mortality. In: Wenner, A. M. Kuris, A. M. (eds.) Crustacean egg production. A. A. Balkama Boston

Kuris, A. M., Blau, S. F., Paul, A. J., Shields, J. D., Wickham, D. E. (1991). Infestation by brood symbionts and their impact on egg mortality of the red king crab, Paralithodes camshatica, in Alaska: geographical and temporal variation. Can. J. Fish. Aquat. Sci. 48: 559-568

Kuris, A. M., Lafferty, K. D. (1992). Modelling crustacean fisheries: effects of parasites on management strategies. Can. J. Fish. Aquat. Sci. 49: 327-336

Lafferty, K. D. (1991). Effects of parasitic castration on the salt marsh snail, Cerithided californica. Ph.D. thesıs, Unjversity of Californa, Santa Barbara

Lafferty, K. D. (1993). The marine snail, Cerithidea californica, matures at smaller sizes where parasitism is high. Oikos (in press)

Lester, R. J. G. (1978). Recent research on Moreton Bay 'mophies' Queensland Commerclal Fisherman's Organization Newsletter: $37-38$

Lie, K. J. (1973). Larval trematode antagonism: principles and possible application as a control method. Exp. Parasitol. 33: $343-349$

MacDonald, K. B. (1969). Quantitatıve studies of salt marsh mollusc faunas from the North American Pacific Coast Ecol. Monogr. 39: 33-60

Margolis, L., Esch, G. W., Holmes, J. C., Kuris, A. M., Schad G. M. (1982). The use of ecological terms in parasitology (report of an ad hoc committee of the American Society of
Parasitologists). J Parasitol. 68: 131-133

Martin, W. E. (1955). Seasonal infections of the snail Centhidea californica Haldeman, with larval trematodes. In: Essays in the natural sciences in honor of Captain Allan Hancock. University of Southern California Press, Los Angeles, p. 203-210

Martin, W. E. (1972). An annotated key to the cercariae that develop in the snail Cerithidea californica. Bull. So. Cal. Acad. Sci. $71: 39-43$

McCloy, M. J. (1979). Population regulation in the depositfeeding mesogastropod Cerithided callfornica as it occurs in a San Diego salt marsh habitat. Master's thesis, California State University, San Diego

O'Brien, J., Van Wyk, P. (1985). Effects of crustacean parasitic cistrators (epicaridean isopods and rhizocephalan barnacles) on growth of crustacean hosts. In: Wenner, A. M. (ed.) Factors in adult growth. A. A. Balkema, Boston, p. $191-218$

Page, H. M., Dugan, J. E. Hubbard, D. M. (1992). Comparative effects of infaunal bivalves on an epibenthic microalgal community. J. exp. mar. Biol. Ecol. 157: 247-262

Page, H M., Lafferty, K. D. (1993). Estuarine and marine invertebrates. In: Page, H. M., Ferren, W. (eds.) Zoological resources of Carpinteria Salt Marsh (in press)

Race, M. S. (1981). Field ecology and natural history of Cerithidea californica in San Francisco Bay. Veliger 24: $18-27$

Race, M. S. (1982). Competitive displacement and predation between introduced and native mud snails. Oecologia 34: $337-347$

Sloan, N. A. (1984). Incidence and effects of parasitism by the rhizocephalan barnacle, Briarosaccus callosus Boschma, in the golden king crab, Lithodes aequispina Benedict, from deep fjords in northern British Columbia, Canada. J. exp. mar. Biol. Ecol. 84: 111-113

Sousa, W. P. (1983). Host life history and the effect of parasitic castration on growth: a field study of Cerithidea californica Haldeman (Gastropoda: Prosobranchia) and its trematode parasites. J. exp. mar. Biol. Ecol. 73: 273-296

Sousa, W P. (1990). Spatial scale and the processes structuring a guild of larval trematode parasites. In: Esch, G., Bush, A., Aho, J. (eds.) Parasite communities: patterns and processes. Chapman and Hall, New York, p. 41-47

Sousa, W. P. (1993). Size-dependent predation on the salt marsh snail, Cerithidea californica Haldeman. J. exp. mar Biol. Ecol. (in press)

Sousa, W P., Gleason, M. (1989). Does parasitic infection compromise host survival under extreme environmental conditions? The case for Cerithidea callornica (Gastropoda: Prosobrancha). Oecologia 80: 456-464

Strickland, J D. H., Parsons, T R. (1968). A practical handbook of seawater analysis. Queen's Printer, Ottawa

Whitlatch, R. B., Obrebski, S. (1980). Feeding selectivity and coexistence in two deposit feeding gastropods. Mar Biol. 58: $219-225$

Wickham, D. E. (1980). Aspects of the life history of Carcinonemertes errans on eggs of the Dungeness crab, Cancer magister. Mar. Biol. 55: 45-53

Yoshino, T P. (1975). A seasonal and histological study of larval Digenea infecting Cerithidea californica (Gastropoda: Prosobranchia) from Goleta Slough, Santa Barbara County, California. Velıger 18: 156-161

Manuscript first received: August 20, 1992

Revised version accepted: April 16, 1993
This article was presented by J. Nybakken, Moss Landing, California, USA 